\title{
How to utilize vegetation survey using drone image and image analysis software
}

Yong-Gu Han', Se-Hoon Jung ${ }^{2}$ and Ohseok Kwon ${ }^{1,3^{*}}$

\begin{abstract}
This study tried to analyze error range and resolution of drone images using a rotary wing by comparing them with field measurement results and to analyze stands patterns in actual vegetation map preparation by comparing drone images with aerial images provided by National Geographic Information Institute of Korea. A total of 11 ground control points (GCPs) were selected in the area, and coordinates of the points were identified. In the analysis of aerial images taken by a drone, error per pixel was analyzed to be $0.284 \mathrm{~cm}$. Also, digital elevation model (DEM), digital surface model (DSM), and orthomosaic image were abstracted. When drone images were comparatively analyzed with coordinates of ground control points (GCPs), root mean square error (RMSE) was analyzed as $2.36,1.37$, and $5.15 \mathrm{~m}$ in the direction of $X, Y$, and $Z$. Because of this error, there were some differences in locations between images edited after field measurement and images edited without field measurement. Also, drone images taken in the stream and the forest and 51 and $25 \mathrm{~cm}$ resolution aerial images provided by the National Geographic Information Institute of Korea were compared to identify stands patterns. To have a standard to classify polygons according to each aerial image, image analysis software (eCognition) was used. As a result, it was analyzed that drone images made more precise polygons than 51 and $25 \mathrm{~cm}$ resolution images provided by the National Geographic Information Institute of Korea. Therefore, if we utilize drones appropriately according to characteristics of subject, we can have advantages in vegetation change survey and general monitoring survey as it can acquire detailed information and can take images continuously.
\end{abstract}

Keywords: Vegetation survey, Actual vegetation map, Drone image, Aerial image, Image analysis software

\section{Introduction}

A drone is an air plane or a helicopter-shaped flying object which flies by radio waves as unmanned aerial vehicle (UAV) or remotely piloted aircraft (RPA) (Lee 2015). Drones were initially developed for the military purpose such as combat or reconnaissance but now they are used in diverse parts including surveillance, transportation, observation, agriculture, and leisure. It is expected that they will be used in more diversified areas in the future. Drones can be classified as fixed wing drones and rotary wing drones according to the method of operation. The most popular fixed wing drone in Korea is eBee developed by Sensefly, a Swiss company. On the other hand, popular

\footnotetext{
* Correspondence: ecoento@knu.ac.kr

'Institute of Plant Medicine, Kyungpook National University, Daegu 41566, South Korea

${ }^{3}$ School of Applied Biosciences, College of Agriculture and Life Sciences Kyungpook National University, Daegu 41566, South Korea

Full list of author information is available at the end of the article
}

rotary wing drones are Phantom series and Inspire series by DJI, a Chinese company. Fixed wing drones and rotary wing drones have some strengths and weaknesses. Fixed wing drones can fly longer than rotary wing drones because of energy efficiency as they fly using air lift force but they need a certain space for taking-off and landing. Although rotary wing drones can take off and land vertically, they can fly for shorter time than fixed wing drones because of low energy efficiency.

Recently, many universities and laboratories have performed various researches on drones. There are studies on topographic survey of open cast mines using relatively cheap drones (Phantom 2 vision+, DJI, China) (Lee and Choi 2015), on comparison of topographic survey results by a fixed wing drone (eBee, SenseFly, Switzerland) and a rotary wing drone (Phantom 2 vision +, DJI, China) (Lee and Choi 2016), and on sight analysis and utilization method (Kim 2014). In particular, many 
Table 1 Specifications of Phantom 3 Professional aircraft used in this study

\begin{tabular}{lll}
\hline Weight & & $1280 \mathrm{~g}$ \\
Flight time & & $23 \mathrm{~min}$ \\
Max. speed & & $16 \mathrm{~m} / \mathrm{s}$ \\
& & (ATTI mode, no wind) \\
Max. flight altitude & & $6000 \mathrm{~m}$ \\
Camera spec. & COMS & Sony EXMOR $1 / 2.3$ \\
& Lens & f/2.8 $(20 \mathrm{~mm}$ ) \\
& FOV & FOV $94^{\circ}$ \\
& ISO range & $100-3200$ \\
& Image size & $4000 \times 3000$ \\
\hline
\end{tabular}

studies have been made in ecology field relating with preparation of actual vegetation map and classification of stands patterns such as monitoring invasive alien species (The National Institute of Ecology 2015), precise vegetation survey in forest swamps (Korea National Arboretum 2015), and a study on forest swamp biotope (Korea National Arboretum 2016).

It is said that images taken by drones have some exterior orientation distortion because of tilting caused by wind or movement and some interior orientation distortion according to camera and lens mounted on the drone. Therefore, the images taken by drones should be corrected (Kim et al. 2015). Additionally, as it is reported that drone images have multicentimeter level higher space resolution compared with satellite images (Tahar et al. 2011, Kim et al. 2015), drones can provide higher resolution images than portal site maps provided by Daum, Naver, or Google or aerial images provided by National Geographic Information Institute of Korea. Especially, the

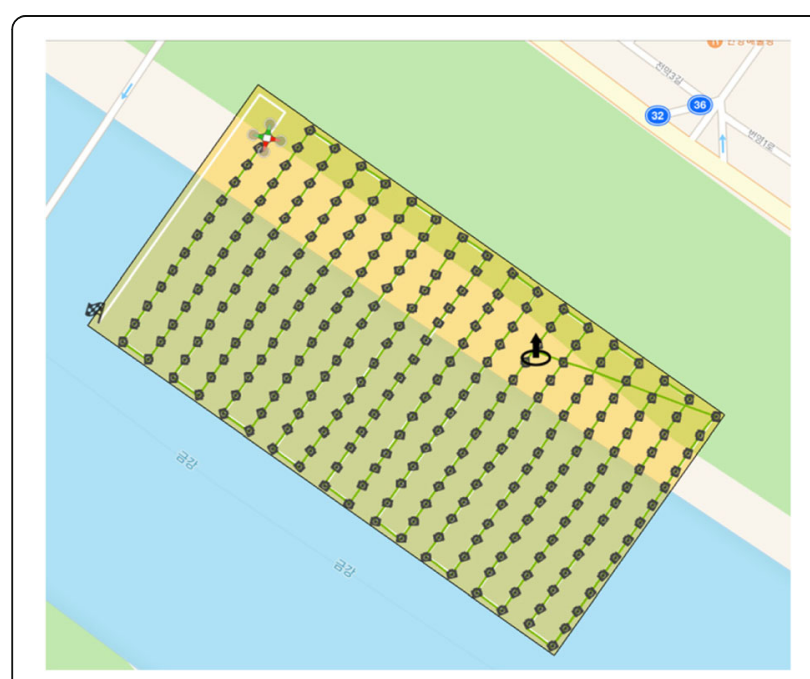

Fig. 1 Automatic flight routes set in the study area
Table 2 Coordinates of the ground control points (GCPs) set in the study area

\begin{tabular}{llll}
\hline ID of GCP & $X(\mathrm{~m})$ & $Y(\mathrm{~m})$ & $Z(\mathrm{~m})$ \\
\hline 1 & $429,893.033$ & $211,724.547$ & 12.074 \\
2 & $429,949.239$ & $211,642.727$ & 12.052 \\
3 & $430,005.625$ & $211,560.625$ & 12.009 \\
4 & $430,064.853$ & $211,474.217$ & 12.039 \\
5 & $429,954.175$ & $211,539.679$ & 10.551 \\
6 & $430,028.262$ & $211,430.257$ & 10.984 \\
7 & $429,959.587$ & $211,356.582$ & 11.326 \\
8 & $429,911.441$ & $211,446.120$ & 10.767 \\
9 & $429,839.064$ & $211,581.880$ & 9.354 \\
10 & $429,858.228$ & $211,628.996$ & 10.426 \\
11 & $429,917.473$ & $211,616.995$ & 10.667 \\
\hline
\end{tabular}

aforementioned aerial images are not current images updated real time so there is a tendency to show different pictures from current status in highly disturbed areas by invasive alien species such as stream or lowland forests. In case of streams, it is difficult to analyze geomorphological landscapes or fine landscapes in the field of mathematical ecology with $1 /$ 25,000 scaled and 1/5000 scaled digital maps distributed by National Geographic Information Institute because the minimal contour line unit is $10 \mathrm{~cm}$ in those maps (Kim 2014). It is supposed that we can save time and efforts while obtaining highly precise survey results if we perform studies based on drone images taken in advance. However, the use of drones in ecological field has been used without any understanding the error range and resolution for each model.

Accordingly, this study tried to analyze error range and resolution of drone images using a most popular rotary wing drone (Phantom 3 Professional, DJI, China) by comparing them with field measurement results and to analyze stands patterns in actual vegetation map preparation by comparing drone images with aerial images provided by National Geographic Information Institute of Korea.

\section{Materials and methods}

Research equipment and subject area

In this study, one of popular drones (Phantom 3 Professional, DJI, China) was used. Its detailed specifications are shown in Table 1. Drone images were taken during the automatic flight using smartphone application provided by DJI (Fig. 1). Images were taken in force land of the right bank of Geum river near Shinkwan-dong, Gongju-si, Chungcheongnam-do, and the forest near Namcheon Camping Ground in Mt. Sobaek National 


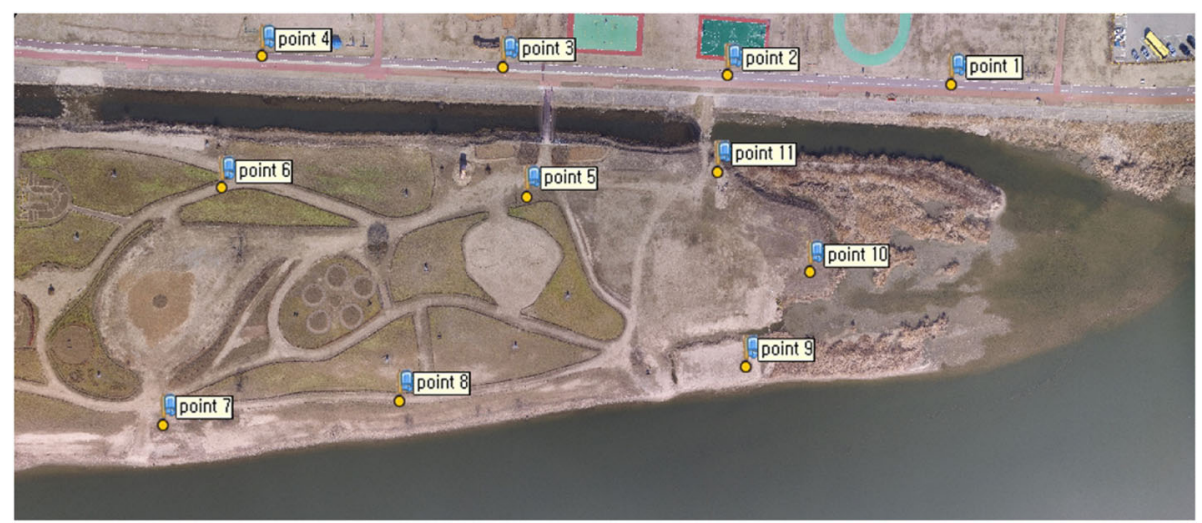

Fig. 2 Locations of ground control points (GCPs) installed in the study area

Park near Namcheon-ri, Youngchun-myeon, Danyanggun, and Chungcheongbuk-do.

\section{Data processing}

Error ranges of drone images were identified by comparing with field measurement results. For field measurements, 11 ground control points (GCPs) were selected in force land of the right bank of Geum river near Shinkwan-dong, Gongju-si, and Chungcheongnam-do. Measurements were finally calibrated after the measurement in the unified control points (UCPs) near the research area. For latitude, longitude, and altitude coordinates of ground control points, VRS/RTK-GPS were used (Table 2).

For vegetation pattern analysis in actual vegetation map, aerial images by National Geographic Information Institute of Korea (51 and $25 \mathrm{~cm}$ grade) and drone images were used. The analysis was made using image analysis software (eCognition, Trimble, USA). Image editing of aerial images taken in the field was performed using photogrammetry software such as Pix4Dmapper Pro (Pix4D, Switzerland) and PhotoScan Professional (Agisoft, Russia). In case of program editing mechanism, a single image can be obtained as each drone image-taking point has a GPS coordinate and a drone takes images overlapped. Additionally, an orthomosaic image can be made as the aforementioned program allows geometric correction by automatic aerial triangulation (AAT) (Siebert and Teizer 2014, Lee and Choi 2015).

\section{Results and discussion}

\section{Analysis of error range and resolution of drone images} through field measurement

To analyze resolution and error range of drone images taken by a popular drone, Phantom 3 Professional, total 11 ground control points were selected in the area
(Fig. 2) and coordinates of the points were identified (Table 2). The height of drones was maintained as $80 \mathrm{~m}$, horizontal and vertical overlapping were set as $80 \%$ respectively, and total area of 10.35 ha was imaged. Picturing time was about $22 \mathrm{~min}$ and total 267 aerial images were taken. It took about $6 \mathrm{~h}$ for an editing program to edit aerial images taken by a drone. Excluding edges, more than five aerial images were overlapped in most cases (Fig. 3). In the analysis of aerial images taken by a drone, error per pixel was analyzed to be $0.284 \mathrm{~cm}$. Digital elevation model (DEM), digital surface model (DSM), and orthomosaic image were abstracted through these data (Fig. 4). Aerial images taken in the subject area had $30 \mathrm{~cm}$ grade resolution and it was analyzed to be similar to $20 \mathrm{~cm}$ resolution images taken by Kim (2014) at the same height in Gapcheon river in Daejeon. When drone images were comparatively analyzed with coordinates of ground control points (GCPs), root mean square error (RMSE) was

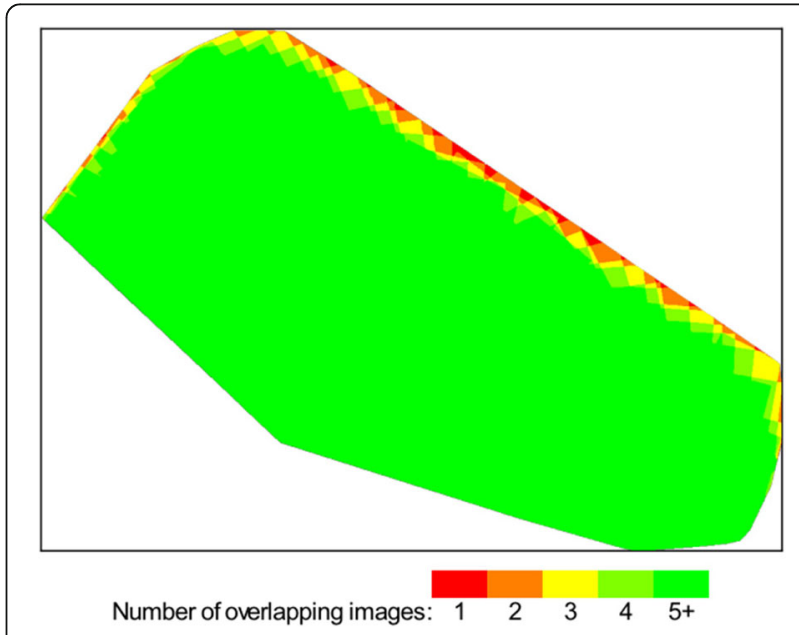

Fig. 3 Number of overlapping images used in the study area 

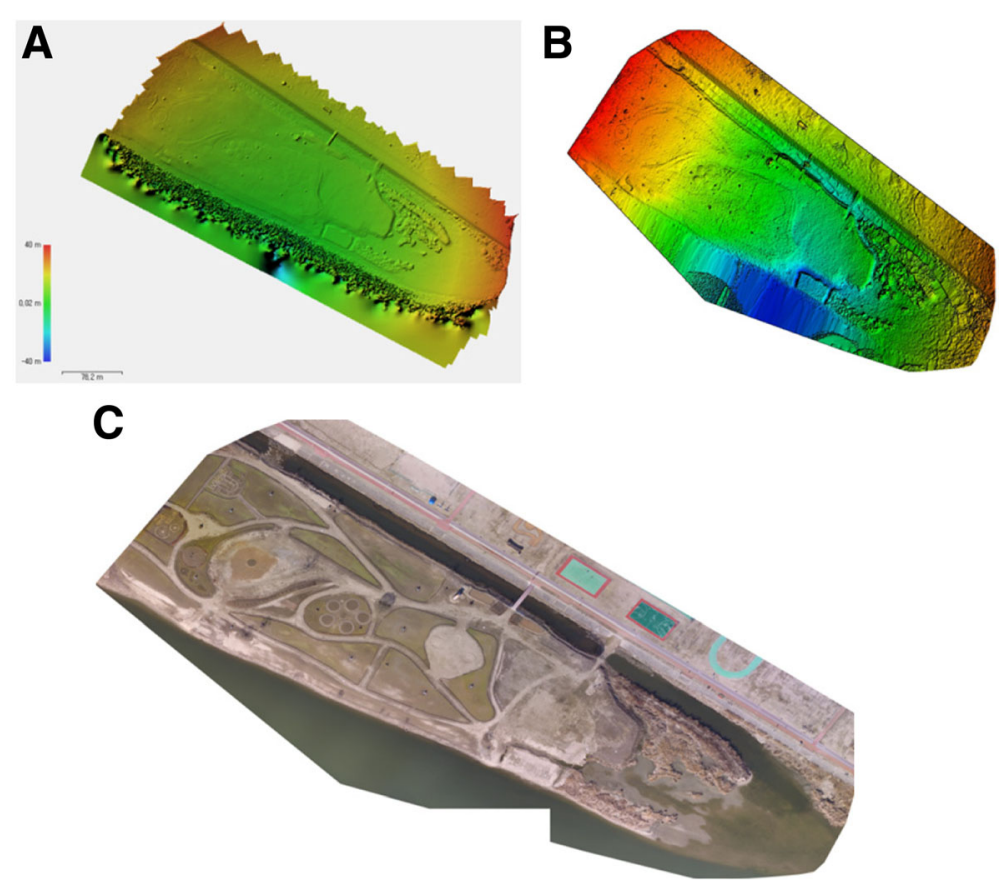

Fig. 4 Results of digital elevation model (DEM; a), digital surface model (DSM; b), and orthomosaic image (c)

analyzed as $2.36,1.37$, and $5.15 \mathrm{~m}$ in the direction of $\mathrm{X}, \mathrm{Y}$, and $\mathrm{Z}$ (Table 3). Because of this error, there were some differences in locations between images edited after field measurement and images edited without field measurement (Fig. 5). Therefore, it is judged that monitoring through field measurement is necessary when precise data are required such as ecology disturbing species distribution monitoring or unusual plant community monitoring.

Table 3 Accuracy of orthomosaic images made from ground control points (GCPs)

\begin{tabular}{llll}
\hline GCPs & $X(\mathrm{~m})$ & $Y(\mathrm{~m})$ & $Z(\mathrm{~m})$ \\
\hline 1 & -2.87 & -0.70 & -10.67 \\
2 & -2.40 & -0.55 & -3.75 \\
3 & -1.87 & -0.94 & -2.02 \\
4 & -1.62 & -1.34 & -6.35 \\
5 & -1.93 & -1.02 & 4.71 \\
6 & -1.52 & -1.83 & -1.86 \\
7 & -1.94 & -2.55 & -2.51 \\
8 & -2.29 & -2.31 & 5.48 \\
9 & -3.22 & -0.65 & 6.99 \\
10 & -3.07 & -0.45 & 2.10 \\
11 & -2.53 & -0.46 & 2.05 \\
Mean & -2.30 & -1.16 & -0.53 \\
RMSE & 2.36 & 1.37 & 5.15 \\
\hline
\end{tabular}

\section{Comparison of community classification according to} aerial images in preparation of actual vegetation map Actual vegetation map which is the basis of vegetation survey diagrams currently distributed vegetation. It can be utilized in various fields such as land development and forest management including phytosociological spatial analysis as it provides precise vegetation information quickly (Kim and Lee 2006). Such actual vegetation map is prepared indoor based on images provided by portal sites such as Daum, Naver, or Google or aerial images provided by $\mathrm{Na}$ tional Geographic Information Institute of Korea before field survey. Communities are divided by bare eye judgment of a vegetation expert and community name is given by identifying dominant species in basic field survey. Therefore, drone images taken in the stream and the forest and 51 and $25 \mathrm{~cm}$ resolution aerial images provided by National Geographic Information Institute of Korea were compared to



Fig. 5 Comparison of image editing errors between images with field measurement and without field measurement 
identify stands patterns. To have a standard to classify polygons according to each aerial image, image analysis software eCognition (Trimble, USA) was used. The software automatically actuates polygons with the same scale for the same area (stream scale parameter: 700, forest scale parameter: 500). It was analyzed that drone images made more precise polygons than 51 and $25 \mathrm{~cm}$ resolution images provided by National Geographic Information Institute of Korea (Fig. 6). It is partly because resolution of drone images is higher than images provided by National Geographic Information Institute of Korea and partly because there was difference in picturing time and weather condition. On the other hand, in case of the stream with heavy seasonal changes and forest edges with high probability of development, aerial images provided by National Geographic Information Institute of Korea or portal sites such as Daum, Naver, and Google are tend to be very much different from current status as they do not provide real time images. Therefore, if we utilize drones appropriately according to characteristics of subject, we can have advantages in vegetation change survey and general monitoring survey as it can acquire detailed information and can take images continuously. Additionally, we may be able to identify area where unusual plants can be shown and vegetation hotspot area in advance and utilize them in the study. It is expected to be actively used in the future as it saves time for survey and returns highly precise research results.
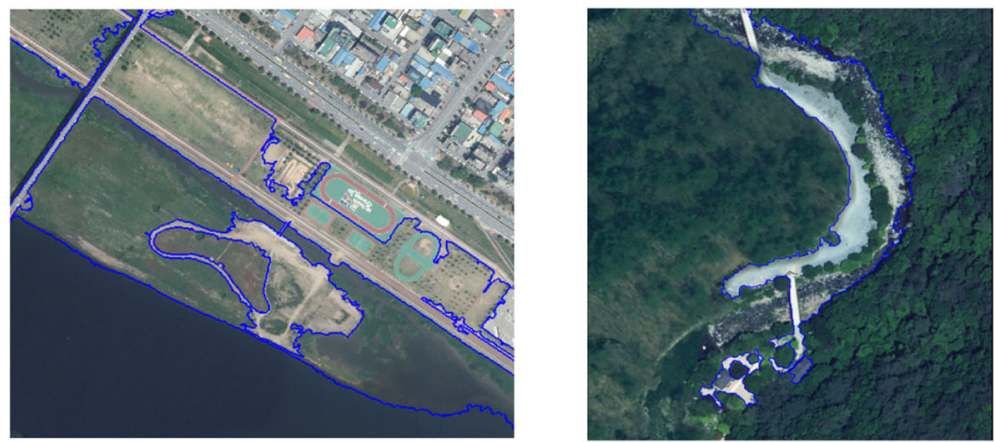

Resolution of $51 \mathrm{~cm}$ grade
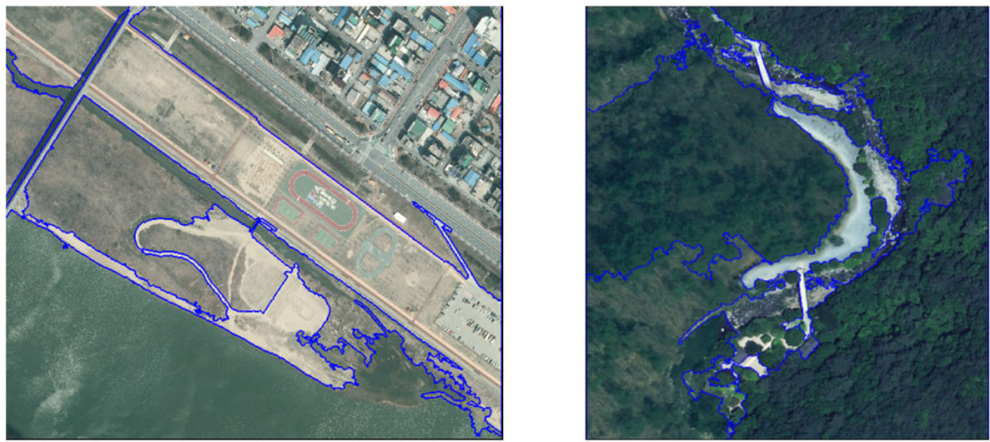

Resolution of $25 \mathrm{~cm}$ grade
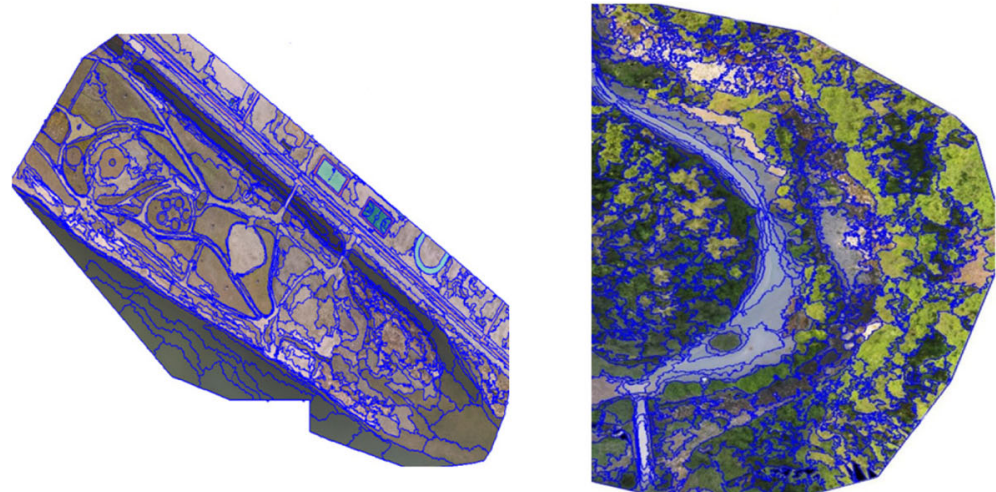

Drone images

Fig. 6 Comparison of stands patterns according to resolution 


\section{Abbreviations}

AAT: Automatic aerial triangulation; DEM: Digital elevation model DSM: Digital surface model; GCPs: Ground control points; RMSE: Root mean square error; RPA: Remotely piloted aircraft; UAV: Unmanned aerial vehicle; UCPS: Unified control points

\section{Acknowledgements}

This subject is supported by Korea Ministry of Environment (MOE) as "Public Technology Program based on Environmental Policy (2014000210003)".

\section{Publisher's Note}

Springer Nature remains neutral with regard to jurisdictional claims in published maps and institutional affiliations.

\section{Funding}

This subject is supported by the Korea Ministry of Environment (MOE) as "Public Technology Program based on Environmental Policy (2014000210003)"

\section{Availability of data and materials}

Not applicable

\section{Authors' contributions}

Y-GH mainly analyzed and interpreted the image data using diverse software and was a major contributor in writing the manuscript. S-HJ mainly collected the image data with the drone and arranged the data using some software to analyze. OK mainly designed this work and revised the paper totally. All authors read and approved the final manuscript.

\section{Competing interests}

The authors declare that they have no competing interests.

\section{Consent for publication}

Not applicable.

\section{Ethics approval and consent to participate}

Not applicable.

\section{Author details}

${ }^{1}$ Institute of Plant Medicine, Kyungpook National University, Daegu 41566, South Korea. ${ }^{2}$ Institute of Ecosystem Restoration Planning, Daejeon 34543 South Korea. ${ }^{3}$ School of Applied Biosciences, College of Agriculture and Life Sciences Kyungpook National University, Daegu 41566, South Korea.

Received: 11 October 2016 Accepted: 31 October 2016

\section{Published online: 17 April 2017}

\section{References}

Arboretum, K. N. (2015). Report of research and monitoring on wetlands of civil owned forest. Pocheon: Korea National Arboretum.

Arboretum, K. N. (2016). Conservation projects of forest wetlands. Pocheon: Korea National Arboretum.

Kim, S. M. (2014). Study of the UAV for application plans and landscape analysis. Journal of the Korean Institute of Traditional Landscape Architecture, 32, 213-220.

Kim, J. W., \& Lee, Y. K. (2006). Classification and assessment of plant communities. Seoul: World Science.

Kim, B. J., Lee, Y. K., \& Choi, J. K. (2015). Investigating applicability of unmanned aerial vehicle to the tidal flat zone. Korean Journal of Remote Sensing, 31, 461-471.

Lee, W. G. (2015). Urban managements using drones. Busan: Busan Development Institute.

Lee, S. J., \& Choi, Y. S. (2015). Topographic survey at small-scale open-pit mines using a popular rotary-wing unmanned aerial vehicle (drone). Tunnel \& Underground space, 25, 462-469.

Lee, S. J., \& Choi, Y. S. (2016). Comparison of topographic surveying results using a fixed-wing and a popular rotary-wing unmanned aerial vehicle (drone). Tunnel \& Underground space, 26, 24-31.

National Institute of Ecology. (2015). Monitoring of invasive alien species designated by the Wildlife Protection Act (II). Seocheon: National Institute of Ecology. Korea.
Siebert, S., \& Teizer, J. (2014). Mobile 3D mapping for surveying earthwork projects using an unmanned aerial vehicle (UAV) system. Automation in Construction, 41, 1-14.

Tahar, K. N., Ahmad, A., \& Wan Mohd Akib, W. A. A. (2011). UAV-based stereo vision for photogrammetric survey in aerial terrain mapping. Penang: Proceedings of IEEE International Conference on Computer Applications and Industrial Electronics.

\section{Submit your next manuscript to BioMed Central and we will help you at every step:}

- We accept pre-submission inquiries

- Our selector tool helps you to find the most relevant journal

- We provide round the clock customer support

- Convenient online submission

- Thorough peer review

- Inclusion in PubMed and all major indexing services

- Maximum visibility for your research

Submit your manuscript at www.biomedcentral.com/submit
) BioMed Central 